\title{
The Relation between Role of Serum Cortisol Level and Response to Various Respiratory Support Strategies among Preterm Infants
}

\author{
Amani E. Arafa1, Safaa A. ElMeneza ${ }^{2}$, Shaimaa A. EL Hafeez ${ }^{3}$ \\ ${ }^{1}$ Sheikh Zayed Hospital, Department of Pediatrics, Giza, Egypt \\ ${ }^{2}$ Department of Pediatrics, Faculty of Medicine for Girls Al-Azhar University, Cairo, Egypt \\ ${ }^{3}$ Department of Clinical Pathology, Faculty of Medicine for Girls Al-Azhar University, Cairo, Egypt \\ Email: amaniebrahim58@gmail.com
}

How to cite this paper: Arafa, A.E., ElMeneza, S.A. and EL Hafeez, S.A. (2020) The Relation between Role of Serum Cortisol Level and Response to Various Respiratory Support Strategies among Preterm Infants. Open Journal of Pediatrics, 10, 504-514.

https://doi.org/10.4236/ojped.2020.103051

Received: August 6, 2020

Accepted: August 18, 2020

Published: September 11, 2020

Copyright $\odot 2020$ by author(s) and Scientific Research Publishing Inc. This work is licensed under the Creative Commons Attribution International License (CC BY 4.0).

http://creativecommons.org/licenses/by/4.0/

\begin{abstract}
Introduction: Preterm infants are liable to various health problems including respiratory distress syndrome (RDS). There is variation in response to respiratory support. In preterm infants, cortisol hormone is secreted by the adrenocortical gland in response to stress. Objectives: To compare the serum cortisol levels in blood among preterm infants who needed different respiratory support strategies e.g. headbox, continuous positive airway pressure (CPAP), intubation surfactant extubation (INSURE) and mechanical ventilation (MV) and to correlate the cortisol levels to the severity of respiratory distress syndrome (RDS). Material and Methods: Observational prospective study that assessed the serum cortisol levels in preterm infants with RDS after initial respiratory support aged 28 - 34 gestational weeks that were admitted to the neonatal intensive care unit of $\mathrm{Al}$ Zahraa hospital of Al-Azhar University and Al-Estekama hospital between February 2019 and November 2019. Infants were classified into three groups, Group 1: 29 infants with severe RDS who needed a mechanical ventilator. Ten of them needed surfactant therapy. Group 2: 33 infants with moderate RDS who needed CPAP. Three of them needed surfactant therapy. Group 3: 28 infants with symptoms of mild RDS who needed headbox. None of them needed surfactant therapy. Blood samples were collected on the first day of life and were processed using the colorimetric ELISA method. Demographic and medical information was collected. Results: A total of 90 preterm infants were included. The serum cortisol reference was $4.3-22.4 \mathrm{mg} / \mathrm{dl}$. Group 1 showed significantly higher serum cortisol levels compared to group 2 and group $3(39.22 \pm 9.91 \mathrm{mg} / \mathrm{dl}$ vs $28.96 \pm 6.48 \mathrm{mg} / \mathrm{dl}$ vs $25.88 \pm 5.42 \mathrm{mg} / \mathrm{dl})$ respectively, $(\mathrm{P}$-value $=0.001)$. In-
\end{abstract}


fants in group 2 who needed surfactant therapy had higher serum cortisol levels than those who did not need surfactant therapy $(32.30 \pm 5.92 \mathrm{mg} / \mathrm{dl}$ vs $28.33 \pm 6.27 \mathrm{mg} / \mathrm{dl}$ ). The serum cortisol levels were observed having a negative correlation with gestational age and birth weight. No significant differences were observed in terms of gender or type of delivery. Conclusion: Cortisol levels had a positive correlation with the severity of RDS who needed various respiratory support strategies.

\section{Keywords}

Respiratory Distress Syndrome, Cortisol, Preterm, Respiratory Support

\section{Introduction}

Preterm infants are liable to various health problems including respiratory distress syndrome (RDS). There is variation in response of preterm infants with the same gestational age to respiratory support, some may respond to oxygen, others may need intubation surfactant extubation (INSURE), continuous positive airway pressure (CPAP) or mechanical ventilator (MV) [1] [2]. The cortisol produced by the adrenal cortex changes structurally and functionally along with gestational age and maturation of the adrenocortical gland function. Cortisol increases after late gestation ( 32 - 36 weeks). However, in preterm infants, the adrenocortical gland secrets cortisol in response to stress [3]. RDS develops respiratory distress due to impaired synthesis and secretion of the surfactant and affects mostly preterm infants [4] [5]. Surfactant prevents the alveoli from collapsing during expiration and helps gas exchange [6]. Acute illnesses as RDS and infection influence the hypothalamic-pituitary-adrenal axis (HPA axis) [7]. Available information on the endogenous cortisol levels of preterm infants and their response to respiratory support strategies in our country is limited. Therefore, the objective of this study is to compare the endogenous cortisol levels among preterm infants with the severity of RDS, who needed respiratory support (e.g. headbox, CPAP, INSURE and MV) and to correlate the cortisol levels to the severity of RDS.

\section{Patients and Methods}

\subsection{Study Design and Settings}

This is an observational prospective study that assessed the serum cortisol levels in preterm infants with RDS after initial respiratory support aged 28 - 34 gestational weeks. They were admitted to the neonatal intensive care unit of $\mathrm{Al} \mathrm{Za-}$ hraa hospital of Al-Azhar University and Al-Estekama hospital between February 2019 and November 2019. A total of 90 preterm infants were included in this study. Demographic data and medical history were collected. Infants were classified into three groups: Group 1: 29 infants with severe RDS who needed a me- 
chanical ventilator. Ten of them needed surfactant therapy. Group 2: 33 infants with moderate RDS who needed CPAP. Three of them needed surfactant therapy. Group 3: Infants with symptoms of mild RDS who needed headbox. None of them needed surfactant therapy.

\subsection{Inclusion Criteria}

The study included infants who suffered from RDS with various degrees and inappropriate weight for gestational age.

\subsection{Exclusion Criteria}

1) Infants with major congenital malformations;

2) Infants with endocrine abnormality;

3) Neonatal asphyxia;

4) Infants with adrenal hemorrhage;

5) Neonatal infection;

6) Neonatal persistent hypoglycemia;

7) Mothers with hypertension;

8) Maternal history of endocrine disorders such as diabetes, thyroid, or adrenal problems;

9) Mothers on chronic steroid treatment;

10) Maternal history alcohol during pregnancy.

\subsection{Laboratory Investigation}

Blood samples were taken on the 1st day of life in a sterile tube, was left to clot, and then was centrifuged at $3000 \mathrm{rpm}$. The serum was separated and stored at $-20^{\circ} \mathrm{C}$ till the time of assay. The samples were tested using colorimetric ELISA (Cortisol AccuBind ELISA Kit), reference: (4.3 - 22.4) mg/dl.

\subsection{Statistical Analysis}

Statistical analysis was performed for 90 preterm infants by using Statistical Package for the Social Sciences software (SPSS) 20.0 program. Cortisol levels were analyzed using the chi-square test, unpaired student t-test, and Mann-Whitney U-test. The linear correlation coefficient was used for the detection of a correlation between two quantitative variables in one group. The correlation coefficient was accepted as 0.05 .

\subsection{Ethical Approval}

Informed consent was obtained for each participant. Ethical approval was obtained from the Institutional Review Board at Al-Zahraa university hospital and Al-Estekama hospital.

\section{Results}

A total of 90 infants were included in the study, 29 in group 1, 33 in group 2, and 
28 in group 3. Concerning the gender composition of the subjects, 35 are females $(38.89 \%)$ and 55 of them are males $(61.11 \%)$. Besides, the demographics of the groups are shown in Table 1. One notable difference between the three groups is the gestational age: the infants in group 3 score significantly higher than the infants in groups 1 and 2.

Serum cortisol level was evaluated on the 1st day of life as shown in Table 2. The mean cortisol level in group 1 is $39.22 \mathrm{mg} / \mathrm{dl}$ with a standard deviation (SD) of 9.91 . This was significantly higher than group 2 , with the average $28.96 \mathrm{mg} / \mathrm{dl}$, and standard deviation 6.48 and group 3, with the average $25.88 \mathrm{mg} / \mathrm{dl}$ and standard deviation 5.42 as shown in Figure 1. There is a negative correlation between serum cortisol levels and age as well as birth weight as shown in Figure 2.

On the other hand, ROC curve of cortisol levels and the severity of RDS is shown in Figure 3. The cutoff point of cortisol level is 28.7. The sensitivity and specificity were $96 \%$ and $61.54 \%$, respectively.

There were no significant differences observed in serum cortisol levels in terms of the gender $(P=0.074)$ or the mode of delivery $(P=0.407)$ : both p-values fall short of statistical significance.

The mean cortisol levels were significantly higher in infants with severe RDS in group 1 compared to other preterm infants $(\mathrm{P}=0.001)$ (Table 3$)$.

Table 1. Demographic data of the studied groups.

\begin{tabular}{|c|c|c|c|c|c|c|}
\hline & & \multirow{2}{*}{$\begin{array}{c}\text { Group } 1 \\
\text { Ventilator } \\
(\mathrm{N}=29)\end{array}$} & \multirow{2}{*}{$\begin{array}{c}\text { Group } 2 \\
\text { CPAP } \\
(\mathrm{N}=33)\end{array}$} & \multirow{2}{*}{$\begin{array}{l}\text { Group } 3 \\
\text { headbox } \\
(\mathrm{N}=28)\end{array}$} & \multicolumn{2}{|c|}{ Chi-Square Test/One-Way ANOVA } \\
\hline & & & & & $\mathrm{X}^{2} / \mathrm{f}^{*}$ & P-value \\
\hline \multirow{3}{*}{ Gender } & Female & $7(24.1 \%)$ & $13(39.4 \%)$ & $15(53.6 \%)$ & \multirow{3}{*}{5.199} & \multirow{3}{*}{0.074} \\
\hline & & & & & & \\
\hline & Male & $22(75.9 \%)$ & $20(60.6 \%)$ & $13(46.4 \%)$ & & \\
\hline GA (weeks) & Mean \pm SD & $31.28 \pm 2.28$ & $32.85 \pm 1.70$ & $33.82 \pm 0.39$ & 16.973 & $<0.001$ \\
\hline \multirow{2}{*}{$\begin{array}{l}\text { Mode of } \\
\text { Delivery }\end{array}$} & C.S $(\mathrm{N}=\%)$ & $24(82.8 \%)$ & $24(72.7 \%)$ & $24(85.7 \%)$ & \multirow[b]{2}{*}{1.8} & \multirow[b]{2}{*}{0.407} \\
\hline & N.V.D $(\mathrm{N}=\%)$ & $5(17.2 \%)$ & $9(27.3 \%)$ & $4(14.3 \%)$ & & \\
\hline Weight (kg) & Mean \pm SD & $1.84 \pm 0.53$ & $1.90 \pm 0.35$ & $2.38 \pm 0.29$ & 15.132 & $<0.001$ \\
\hline Length $(\mathrm{cm})$ & Mean \pm SD & $41.63 \pm 2.92$ & $43.12 \pm 2.03$ & $44.66 \pm 1.37$ & 13.530 & $<0.001$ \\
\hline
\end{tabular}

$\mathrm{F}^{*}=$ one-way ANOVA; $\mathrm{x}^{2}=$ Chi square test; GA: gestational age.

Table 2. Cortisol levels (mg/dl) on the $1^{\text {st }}$ day in the studied groups.

\begin{tabular}{|c|c|c|c|c|c|c|c|c|}
\hline & \multicolumn{2}{|c|}{$\begin{array}{c}\text { Group } 1 \\
\text { Ventilator } \\
(\mathrm{N}=29)\end{array}$} & \multicolumn{2}{|c|}{$\begin{array}{l}\text { Group } 2 \\
\text { CPAP } \\
(\mathrm{N}=33)\end{array}$} & \multicolumn{2}{|c|}{$\begin{array}{l}\text { Group } 3 \\
\text { Headbox } \\
(\mathrm{N}=28)\end{array}$} & \multicolumn{2}{|c|}{ One-way ANOVA } \\
\hline & Mean & SD & Mean & SD & Mean & SD & F & $P$-value \\
\hline Cortisol level (mg/dl) & 39.22 & 9.91 & 28.96 & 6.48 & 25.88 & 5.42 & 25.131 & 0.001 \\
\hline
\end{tabular}




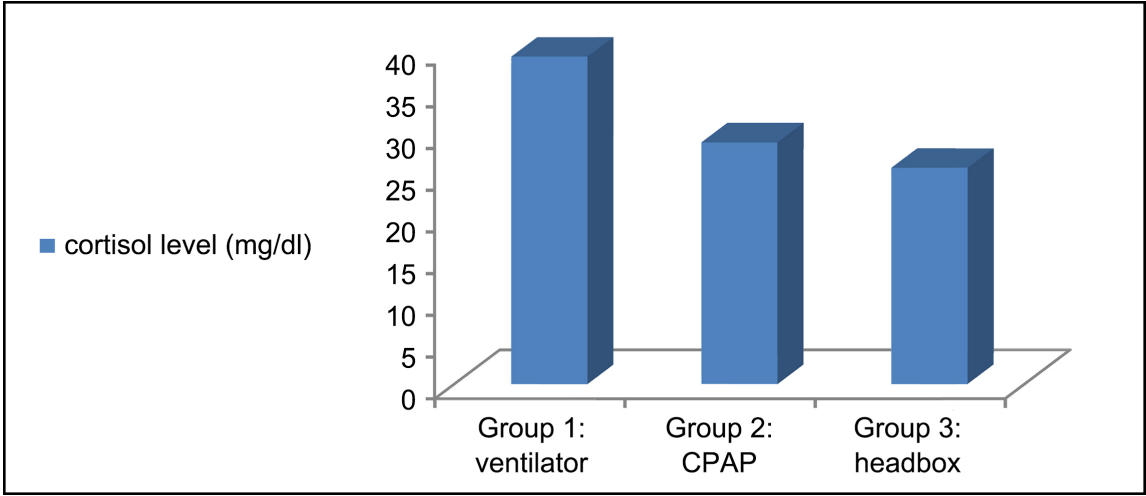

Figure 1. Serum cortisol level among studied groups on the first day after birth.

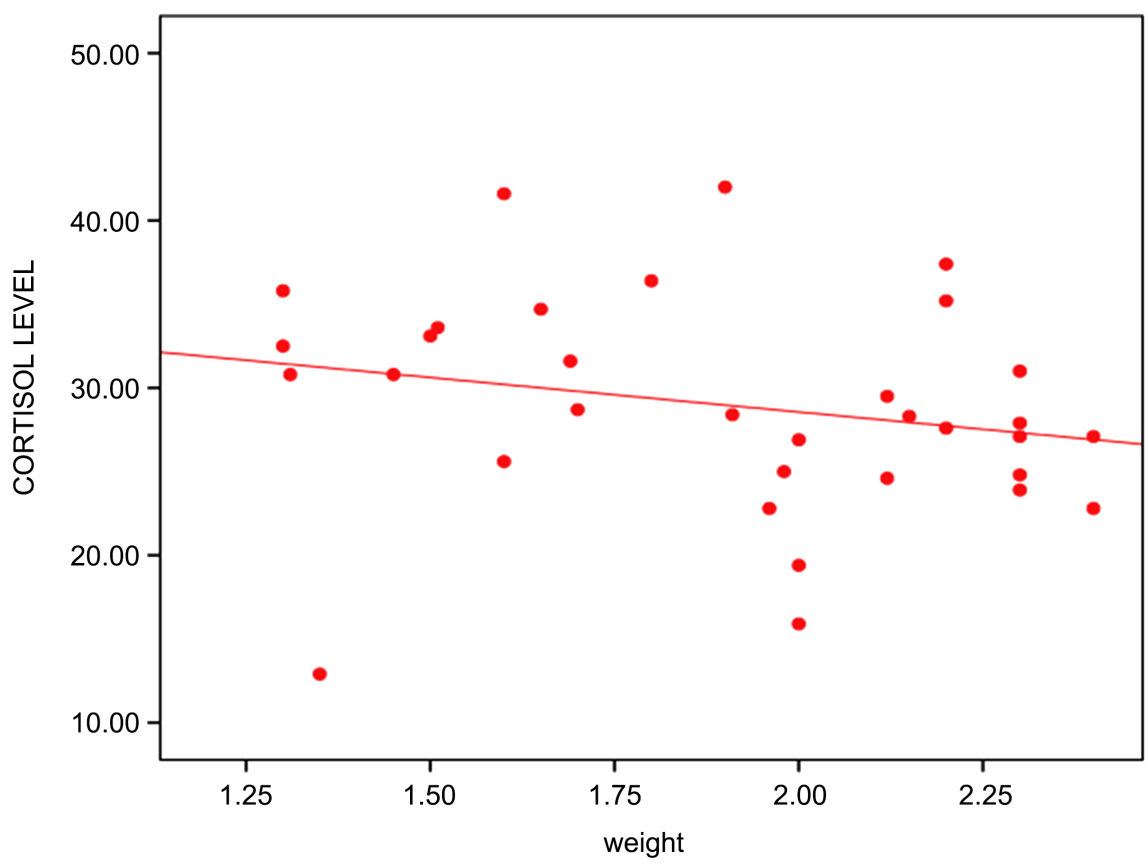

Figure 2. Negative correlation between serum cortisol level and weight.

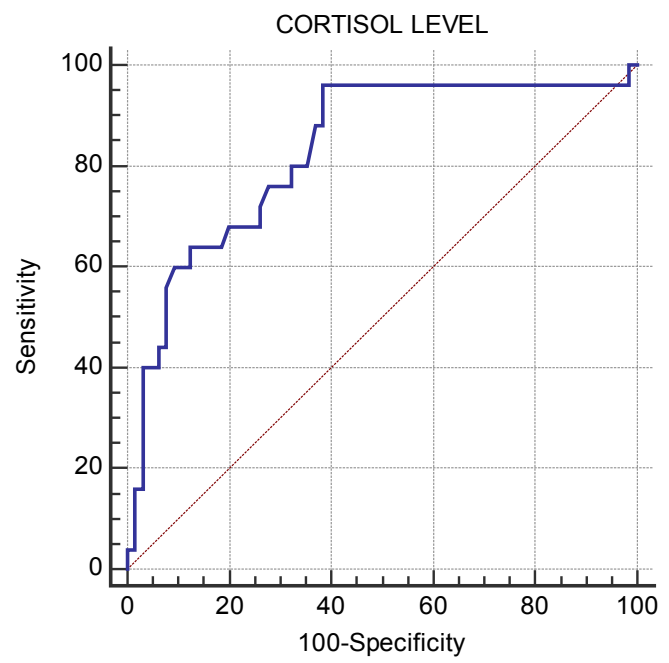

Figure 3. ROC curve of cortisol level and severity of RDS. 
Preterm infants who needed surfactant therapy among group 2 had higher cortisol levels compared to those who did not need surfactant therapy in the same group $(P$-value $=0.045)$. However, the infants who needed surfactant therapy in group 1 did not show any significant difference in cortisol levels compared to those who did not need surfactant therapy in the same group $(\mathrm{P}=$ 0.087) (Table 4).

There was a significant increase in serum cortisol levels in infants who developed complications: intra ventricular hemorrhage, bronchopulmonary dysplasia and, mortality $(\mathrm{P}$-value $=0.001,0.001$, and 0.032 respectively) $($ Table 5$)$.

ROC curve of cortisol levels and the mortality is shown in Figure 4 . The cutoff point of cortisol level is 28.4 . The sensitivity and specificity were $91.89 \%$ and $69.81 \%$, respectively.

Table 3. The relation between the severity of RDS and cortisol level.

\begin{tabular}{|c|c|c|c|c|c|c|c|c|}
\hline \multirow{2}{*}{$\begin{array}{l}\text { Severity of RDS } \\
\text { by Down's score }\end{array}$} & \multirow{2}{*}{ N. } & \multirow{2}{*}{$\%$} & \multicolumn{3}{|c|}{ Types of respiratory support } & \multirow{2}{*}{$\begin{array}{c}\text { Cortisol } \\
\text { level mg/dl }\end{array}$} & \multicolumn{2}{|c|}{ One-way ANOVA } \\
\hline & & & Ventilator & CPAP & Headbox & & $\mathbf{F}$ & P-value \\
\hline Mild & 30 & 33.3 & 0 & 2 & 28 & 25.51 & & \\
\hline Moderate & 31 & 34.4 & 5 & 26 & 0 & 30.39 & 20.185 & 0.001 \\
\hline Severe & 29 & 32.2 & 24 & 5 & 0 & 38.28 & & \\
\hline
\end{tabular}

RDS was graded by Down's scoring into mild (1 - 3) moderate $(4-6)$ and severe $(7-10)$.

Table 4. Cortisol level (mg/dl) in babies who needed surfactant therapy versus who did not need surfactant therapy.

\begin{tabular}{|c|c|c|c|c|c|c|}
\hline \multirow[t]{2}{*}{ Group 1: Ventilator } & \multicolumn{2}{|c|}{$\begin{array}{l}\text { Ventilator without Surfactant } \\
\qquad(\mathrm{N}=19)\end{array}$} & \multicolumn{2}{|c|}{$\begin{array}{l}\text { Ventilator with Surfactant } \\
\qquad(\mathrm{N}=10)\end{array}$} & \multicolumn{2}{|c|}{ Independent $t$-test } \\
\hline & Mean & SD & Mean & SD & $\mathrm{T}$ & P-value \\
\hline Cortisol level (mg/dl) & 34.80 & 11.03 & 41.32 & 4.66 & 1.776 & 0.087 \\
\hline \multirow[t]{2}{*}{ Group 2: CPAP } & \multicolumn{2}{|c|}{$\begin{array}{l}\text { CPAP without surfactant } \\
\qquad(\mathrm{N}=30)\end{array}$} & \multicolumn{2}{|c|}{$\begin{array}{l}\text { CPAP with surfactant } \\
\qquad(\mathrm{N}=3)\end{array}$} & \multicolumn{2}{|c|}{ Independent $t$-test } \\
\hline & Mean & $\mathrm{SD}$ & Mean & SD & $\mathrm{T}$ & P-value \\
\hline Cortisol level (mg/dl) & 28.33 & 6.27 & 32.30 & 5.92 & -1.842 & 0.045 \\
\hline
\end{tabular}

Table 5. Comparison between cortisol levels as regards outcome.

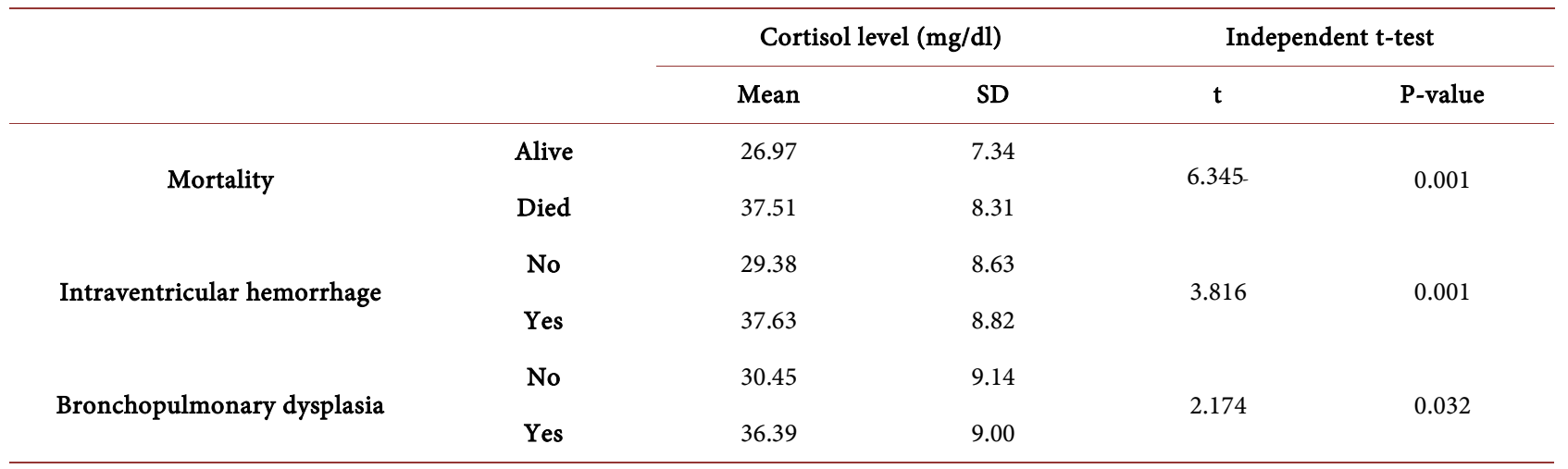




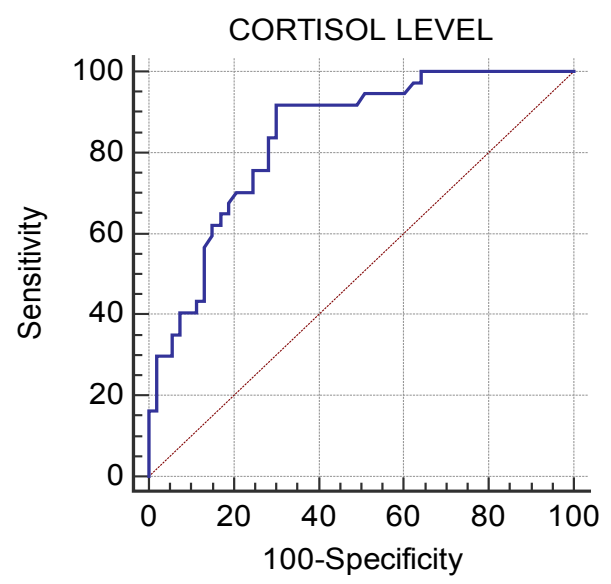

Figure 4. ROC curve of cortisol level and mortality.

\section{Discussion}

This study aimed to compare the serum cortisol concentrations among preterm infants who needed different respiratory support strategies (e.g. headbox, CPAP, Insure, and MV), and correlate the cortisol level to the grade of severity of RDS and response to respiratory support. Our prospective observational study suggests that there is a positive correlation between the cortisol levels in preterm infants with RDS who needed various respiratory support strategies. Our results are consistent with another study that found an association between ventilation and high cortisol levels in preterm infants [8].

There was a significant increase in cortisol levels in group 1 compared to other groups. Elevated serum cortisol levels in infants on MV have shown that infants with RDS produce more cortisol than normal infants to cope with poor lung functions. Cortisol might have been released due to the pain or the stress of the intubation procedure itself [9]. (Grofer et al., 2010) reported that there was a positive association between the rate of cortisol production and severity of illness in preterm infants aged $(30-36)$ gestational weeks [10]. We have found that the cutoff point of cortisol level is 28.7 regarding the severity of RDS. The severity of the respiratory distress syndrome was assessed by Downes score that determines the progression of the respiratory distress and also used to predict the requirement of the respiratory support, mechanical ventilation and mortality in neonates with the respiratory distress [11]. The sensitivity and specificity were $96 \%$ and $61.54 \%$, respectively.

There was a significant increase in the birth weight and mean serum cortisol level in group 3 compared to the group 1 and group 2 (P-value $<0.001$ ). This agreed with studies that found an inverse association between the birth weight and RDS [12] [13], and another study found that preterm with lower birth weight had higher serum cortisol [14]. In the present study, we observed that the cortisol levels within group 2 of infants who needed surfactant therapy were higher than those in the same group who did not need surfactant therapy. However, there was no significant association between cortisol levels and surfactant 
therapy in group 1 of infants on MV. There is another study indicated that the surfactant therapy had no clinical respiratory benefit for intubated preterm infants at any dose [15].

Besides, we found that the cortisol levels were inversely related to gestational age. The cortisol levels were higher in infants with a gestational age of 32 weeks or less. This agreed with other studies which observed the relation between gestational age and serum cortisol levels [16] [17].

This can be explained by two factors: 1) reduction of tissue sensitivity to the cortisol with decreasing gestational age thus the body needs higher cortisol level to be able to do the same physiological functions during early neonatal life; and 2) reduction of cortisol degradation and immature adrenal enzymes with the lower gestational age [18].

Male infants were the predominant in this study. However, there was no significant difference in serum cortisol levels or RDS severity regarding the gender. $(\mathrm{P}$-value $=0.074)$. Our findings agreed with other studies that showed that the age of infants with RDS had no effect on the severity of RDS [19]. Estrogen improves fetal lung development by increasing the number of alveolar type II cells and also by increasing the formation of lamellated bodies. In contrast, androgen delays the secretion of fibroblast-pneumocyte factor like dihydrotestosterone and decreases the synthesis of phosphatidylcholine in the fetal lung, that may delay the development of alveolar type II cells and may reduce surfactant releases, thus it increases the incidence of RDS [20].

In addition, our study found that the mode of delivery did not show any significant association with the serum cortisol levels. This goes with another study that mentioned the same result [21].

Our study found that higher cortisol levels were associated with cases developed complications as intra ventricular hemorrhage, and chronic lung disease [22]. The cutoff point of cortisol level is 28.4. The sensitivity and specificity were $91.89 \%$ and $69.81 \%$, respectively. Other studies reported that infants with severe intraventricular hemorrhage or chronic lung disease had higher serum cortisol levels [14] [16].

Early non-invasive treatment of RDS among preterm infants may decrease adverse events and complications and improve patient safety [23] [24].

In this study, cortisol was measured after the initial respiratory support has started, and thus, not only RDS severity but also ventilation-support procedure may have affected the cortisol level. The present study could not distinguish these two. However, generally speaking, the severer the RDS is, the more invasive the respiratory therapy becomes, and thus, the present context is still reasonable, we believe.

\section{Conclusion}

In conclusion, serum cortisol levels in preterm infants seem to be correlated to the severity of RDS and preterm infants who need respiratory support. Besides, 
there is an inverse association of the cortisol levels with gestational age and birth weight. No significant differences were observed in terms of the gender or the mode of delivery. We can use the 1st-day serum cortisol level as a simple way to predict the severity of RDS, the respiratory support strategy needed and the short-term outcome of preterm with RDS.

\section{Acknowledgements}

I would like to express my special thanks to Dr. Yasser Ahmed Kamel Ahmed Atlem who helped me collecting data about targeted group of patients and also for his valuable support and advice while writing the paper.

\section{Conflicts of Interest}

The authors declare no conflicts of interest regarding the publication of this paper.

\section{References}

[1] Welty, S.E., Rusin, C.G., Stanberry, L.I., Mandy, G.T., Gest, A.L., Ford, J.M., Smith, C.V., et al. (2018) Short Term Evaluation of Respiratory Effort by Premature Infants Supported with Bubble Nasal Continuous Airway Pressure Using Seattle-PAP and a Standard Bubble Device. PLOS ONE, 13, e0193807. https://doi.org/10.1371/journal.pone.0193807

[2] ELMeneza, S. and Gaber, A. (2014) Study of Pressure Volume Loop in Relation to Radiological Findings among Ventilated Newborn Infants. Journal of Neonatal Biology, 3, Article ID: 1000130.

https://www.longdom.org/open-access/study-of-pressure-volume-loop-in-relation-t o-radiological-findings-among-ventilated-newborn-infants-2167-0897.1000130.pdf

[3] Busada, J.T. and Cidlowski, J.A. (2017) Mechanisms of Glucocorticoid Action during Development. In: Current Topics in Developmental Biology, Vol. 125, Academic Press, Cambridge, 147-170. https://doi.org/10.1016/bs.ctdb.2016.12.004

[4] Liu, J., Cao, H.Y. and Sorantin, E. (2018) Pneumothorax of the Newborn. In: Neonatal Lung Ultrasonography, Springer, Dordrecht, 111-121. https://doi.org/10.1007/978-94-024-1549-0_9

[5] Ho, J.J., Subramaniam, P. and Davis, P.G. (2015) Continuous Distending Pressure for Respiratory Distress in Preterm Infants. Cochrane Database of Systematic Reviews, No. 7, CD002271. https://doi.org/10.1002/14651858.CD002271.pub2

[6] Somaschini, M., Presi, S., Ferrari, M., Vergani, B. and Carrera, P. (2018) Surfactant Proteins Gene Variants in Premature Newborn Infants with Severe Respiratory Distress Syndrome. Journal of Perinatology, 38, 337-344. https://doi.org/10.1038/s41372-017-0018-2

[7] Chu, B., Marwaha, K. and Ayers, D. (2019) Physiology, Stress Reaction. In: StatPearls [Internet], StatPearls Publishing, Treasure Island, 401, 4.

[8] Wang, L., Chen, L., Li, R., Zhao, J., Wu, X., Li, X. and Shi, Y. (2015) Efficacy of Surfactant at Different Gestational Ages for Infants with Respiratory Distress Syndrome. International Journal of Clinical and Experimental Medicine, 8, 13783-13789.

[9] Gunes, T., Koklu, E., Ozturk, M.A., Koklu, S. and Cetin, N. (2006) Evaluation of Serum Cortisol Levels in a Relatively Large and Mature Group of Ventilated and 
Nonventilated Preterm Infants with Respiratory Distress Syndrome. American Journal of Perinatology, 23, 335-340. https://doi.org/10.1055/s-2006-948222

[10] Grofer, B., Bödeker, R.H., Gortner, L. and Heckmann, M. (2010) Maturation of Adrenal Function Determined by Urinary Glucocorticoid Steroid Excretion Rates in Preterm Infants of More than 30 Weeks of Gestational Age. Neonatology, 98, 200-205. https://doi.org/10.1159/000285571

[11] ELMeneza, S.A., Abu-Shady, M.A., Aref, M. and Elbaseer, A.N.A. (2018) Neutrophil CD64 as Marker to Differentiate Early Sepsis from Noninfectious Respiratory Disorders in Newborn Infants. Acta Scientific Paediatrics, 1, 10-15. https://www.actascientific.com/ASPE/pdf/ASPE-01-0018.pdf

[12] Brincat, M.R., Sant, M. and Calleja, N. (2017) Optimal Gestational Age for Delivery in Uncomplicated Dichorionic Twin Pregnancies: A Population-Based Study.

[13] Condò, V., Cipriani, S., Colnaghi, M., Bellù, R., Zanini, R., Bulfoni, C., Mosca, F., et al. (2017) Neonatal Respiratory Distress Syndrome: Are Risk Factors the Same in Preterm and Term Infants? The Journal of Maternal-Fetal \& Neonatal Medicine, 30, 1267-1272. https://doi.org/10.1080/14767058.2016.1210597

[14] Yilmaz, E.H., Yilmaz, B., Firat, D.B. and Burak, F. (2019) The Relationship of Blood Prolactin, Cortisol and Thyroid Hormones in Prematural Newborns with Respiratory Distress Syndrome. Research in Pediatrics \& Neonatology, 3, 268. https://doi.org/10.31031/RPN.2019.03.000572

[15] McEvoy, C.T., Ballard, P.L., Ward, R.M., Rower, J.E., Wadhawan, R., Hudak, M.L., Ballard, R.A., et al. (2020) Dose-Escalation Trial of Budesonide in Surfactant for Prevention of Bronchopulmonary Dysplasia in Extremely Low Gestational Age High-Risk Newborns (SASSIE). Pediatric Research, 1-8. https://doi.org/10.1038/s41390-020-0792-y

[16] Ng, P.C., Wong, S.P., Chan, I.H., Lam, H.S., Lee, C.H. and Lam, C.W. (2011) A Prospective Longitudinal Study to Estimate the "Adjusted Cortisol Percentile" in Preterm Infants. Pediatric Research, 69, 511-516. https://doi.org/10.1203/PDR.0b013e31821764b1

[17] Clair, C.S., Norwitz, E.R., Woensdregt, K., Cackovic, M., Shaw, J.A., Malkus, H., Illuzzi, J.L., et al. (2008) The Probability of Neonatal Respiratory Distress Syndrome as a Function of Gestational Age and Lecithin/Sphingomyelin Ratio. American Journal of Perinatology, 25, 473. https://doi.org/10.1055/s-0028-1085066

[18] Sorensen, N.L., Maloney, S.K., Pillow, J.J. and Mark, P.J. (2020) Endocrine Consequences of Circadian Rhythm Disruption in Early Life. Current Opinion in Endocrine and Metabolic Research, 11, 65-71.

https://doi.org/10.1016/j.coemr.2020.02.001

[19] Sonawane, R., Patil, A. and Sonawane, S. (2019) Clinical Profile of Respiratory Distress in Newborn. MVP Journal of Medical Science, 5, 151-155. https://doi.org/10.18311/mvpjms/2018/v5i2/18616

[20] Bouhaddioui, W., Provost, P.R. and Tremblay, Y. (2016) Expression Profile of Androgen-Modulated microRNAs in the Fetal Murine Lung. Biology of Sex Differences, 7, 20. https://doi.org/10.1186/s13293-016-0072-z

[21] Mori, A., Tuli, G., Magaldi, R., Ghirri, P., Tessaris, D., Rinaldi, M., de Sanctis, L., et al. (2019) Plasma Cortisol and ACTH Levels in 416 VLBW Preterm Infants during the First Month of Life: Distribution in the AGA/SGA Population. Journal of Perinatology, 39, 934-940. https://doi.org/10.1038/s41372-019-0381-2

[22] ELMeneza, S., Bahgat, S. and Nasr, A. (2018) Plasma Asymmetric Dimethylarginine Levels in Neonates with Bronchopulmonary Dysplasia Associated with Pulmonary 
Hypertension. Open Journal of Pediatrics, 8, 221-237.

https://doi.org/10.4236/ojped.2018.83024

[23] ELMeneza, S. and Abu-Shady, M. (2019) Anonymous Reporting of Medical Errors from the Egyptian Neonatal Safety Training Network. Pediatrics \& Neonatology, 61, 31-35. https://doi.org/10.1016/j.pedneo.2019.05.008 https://www.pediatr-neonatol.com/article/S1875-9572(19)30029-4/fulltext

[24] ELMeneza, S., Habib, A. and Elsalam, R. (2018) Analysis and Identifying Risk Profile for Medication Errors in the Neonatal Intensive Care Units. EC Paediatrics, 7, 669-684. https://www.ecronicon.com/ecpe/pdf/ECPE-07-00290.pdf 